EPiC Series in Engineering
Volume 3, 2018, Pages 2276-2284
HIC 2018. 13th International
Conference on Hydroinformatics

\title{
Application of Intelligent Water Network in Water Resource Management: Framework And Case
}

\author{
Qingming Wang ${ }^{1 *}$, Yong Zhao ${ }^{1}$, Jiaqi Zhai ${ }^{1}$, Yongnan Zhu ${ }^{1}$, Shan Jiang ${ }^{1}$, \\ Fan $\mathrm{He}^{1}$ \\ ${ }^{1}$ China Institute of Water Resources and Hydropower Research (IWHR) Beijing 100038, \\ P.R.China.. \\ wangqmeiwhr.com
}

\begin{abstract}
Water security is a global challenge, and intelligent water network is an important way for some countries and companies to solve regional water problems. Intelligent water network is a comprehensive and systematic water management platform, with river and lake water connected as a physical basis, through the introduction and adoption of new frontier information technology aids and advanced water management concepts to achieve water cycle and its associated process system and efficient Control as the goal. This paper studies the framework of intelligent water network, and presents three main elements of water physical network, water information network and water dispatching network, and discusses the case in Beijing.
\end{abstract}

\section{Introduction}

China is facing a severe situation of water resources at present. Flood, water supply and demand contradiction, water pollution and water ecological degradation have become the main bottlenecks restricting sustainable development (Nardo A D, et al., 2013; Smith V L, et al, 2000). All kinds of water problems, regardless of their forms, can be attributed to the imbalance of the evolution and regulation of the water cycle system. The practice of water resources development, management and protection is essentially the regulation and management of the water cycle and its accompanying process. As the carrier of water cycle system, water network is the objective foundation of all water cycle regulation behavior and measures (Boulos P F., 2017). Therefore, whether disaster mitigation, water resources allocation, conservation and protection, or construction of the relevant management system, can be unified into the construction of "natural - society" dualistic water network software and hardware system. 
The concept of intelligent water network is based on the above background and put forward. Intelligent water network refers to the modern human society, in order to achieve the goals of the benefits of water, disaster reduction and human water harmony, implementing the software and hardware network system which is dependent on the regulation of the "natural - society" dualistic water cycle process. Intelligent water network engineering construction, including water physical network which composed of various types of flow control infrastructure, water informatization network which constructed with intelligent technology trends and water dispatching network which composed of institutional mechanisms and regulation decision-making (Franchini M, et al., 2016). The intelligent water network project will realize the integration of the three basic water conservancy construction components of the physical foundation, the information system and the decision making system, and will realize the coordination of the main functions of water conservancy and water conservation, water supply protection, ecological maintenance, environmental essence and power generation shipping.

The objective of this paper is to discuss the framework of intelligent water network, and their component parts: water physical network, water information network, and water dispatching network, and then take Beijing as an example to introduce the construction work in intelligent water network.

\section{Study Area}

Since 1999, Beijing has been in a state of continuous drought, the situation of water resources has deteriorated rapidly, and the contradiction between supply and demand of water resources began to focus on the outbreak. In Beijing, the average annual precipitation is only $470 \mathrm{~mm}$, with an average annual water resources of 2.09 billion $\mathrm{m} 3$, an average annual water entry of 464 million $\mathrm{m} 3$, and an average annual outflow of 833 million $\mathrm{m} 3$. The total amount of water resources is insufficient, and the per capita water resources is small. The local water resources in Beijing are poor, which belongs to resource type severe water shortage area. In 2014, the total amount of water resources was 2.18 billion $\mathrm{m} 3$, and the number of permanent residents released by Beijing Municipal Bureau of statistics in 2014 was 21.5 million, so that the water resources per capita was only $94 \mathrm{~m} 3$, which was far lower than the international minimum water shortage per capita $1000 \mathrm{~m} 3$. In order to ensure the water supply, Beijing city formed the water supply pattern, including surface water, groundwater, diverted water, reclaimed water and other water supply, and the deployment system is becoming increasingly complex. The construction of Beijing intelligent water network can form a safe and effective engineering system, intelligent perception monitoring system and intelligent management decisionmaking system. In the process of water management monitoring and forecasting to the whole process of decision-making service system, intelligent water network realizes the integration and promotion of water affairs from data, information, knowledge and wisdom, and improves the management level of modern water affairs. It is an important way to improve the level of social management and public service.

\section{Result and discussion}

\subsection{Analysis of Intelligent Water Network Framework}

Intelligent water network is a comprehensive and systematic water management platform, with river and lake water connected as a physical basis, through the introduction and adoption of new frontier information technology aids and advanced water management concepts to achieve water cycle and its associated process system and efficient Control as the goal. Intelligent network can realize the 
integration of the physical network, water conservancy and water dispatching network information network system, and is another social basic public network into the intelligent era after the power network and the transportation network, and is the water industry for the future of intelligent public service model forward-looking response.

From the macro structure, the intelligent water network is the product of the deep coupling of water physical network, water information network and water dispatching management network, and the above three constitute the basic level system of the intelligent water network. "Natural-society" dualistic physical water network is the material carrier of human flood control practice, and the regulation and feedback effects of human beings on water cycle are carried out on the platform. Water information network is the information technology hardware and software integrated system based on the water physics, on the one hand, it is on the physical network to conduct a comprehensive monitoring and sensing through extensive rainfall, hydrological and engineering layout information collection node, and decision support information in its internal form and its network interface transmission terminal for water supply dispatching management network; on the other hand, it gets the information network released the decision instruction through the operation terminal network, and realizes the decision execution of operations in the IOT technology support and laid in the water conservancy facilities on the automatic control module for interface. Water dispatch network is a system of water management decision-making system, which connects the water information network with the information publishing terminal and the information operation terminal as the interface, obtains the decision support information and releases the regulation instruction, and also can interact with the physical network directly through other ways. The physical network, the information network and the dispatching network have their own network elements, and connect each other through the interface to realize the interaction between the networks, as shown in figure 1.

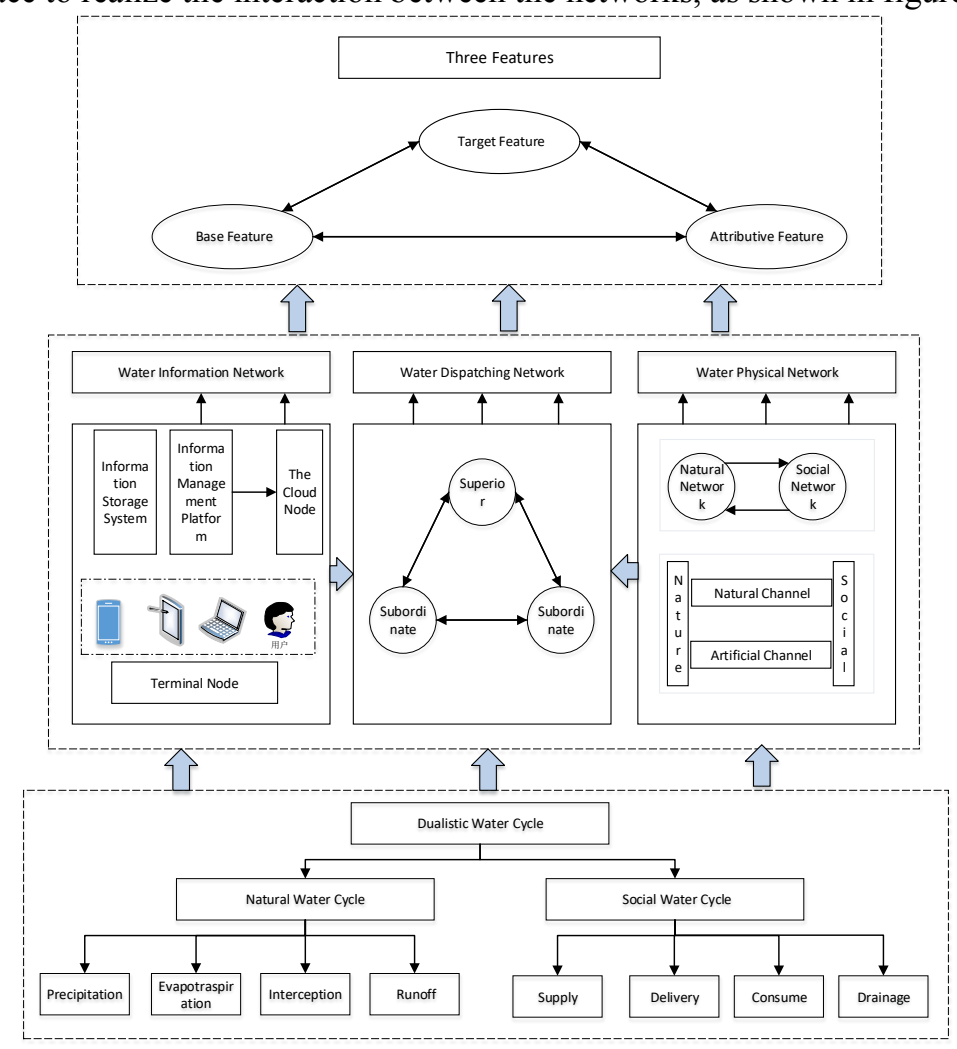

Figure 1 the intelligent water network framework 
Analogous to the body system, the water physical network is equivalent to the body skeleton system of the human body, and the water information network is equivalent to the human nervous system, and the water dispatching network is equivalent to the brain central system. Only when the nervous system is timely perceived, the central system is correctly judged, and the body system sensitive response, the three can work together to achieve the desired behavior or to respond effectively to external stimuli. Therefore, a complete water network is a composite network system formed by the coupling of the above three networks.

Channels, nodes, flows and rules are four basic elements of a network system. For the water physical network, the "channel" is a natural river and artificial drainage system, the "node" is the branch of the binary water cycle network, the "flow" is the water flow, and control the flow of the basic "rules" is Hydrodynamic laws; For the water information network, the "channel" is the information transmission of wired and wireless access, the "node" is including information collection, storage and information management platform, the "flow" is the flow of information, network operation "rules" include data standard, network protocol, transmission protocol etc.; For the water dispatch network, the "channel" is the water administration vertical management and horizontal coordination system, the "node" is different levels of management organizations and institutions, the "flow" is the business flow, and its "rules" by the rules and regulations and scheduling rules composition.

\begin{tabular}{|c|c|c|c|c|}
\hline $\begin{array}{l}\text { Constituent } \\
\text { elements }\end{array}$ & Channel & Node & Flow & Rules \\
\hline $\begin{array}{l}\text { Water } \\
\text { physical } \\
\text { network }\end{array}$ & $\begin{array}{l}\text { A natural river and } \\
\text { artificial drainage } \\
\text { system }\end{array}$ & $\begin{array}{l}\text { The branch of the } \\
\text { binary water cycle } \\
\text { network }\end{array}$ & $\begin{array}{l}\text { The water } \\
\text { flow }\end{array}$ & $\begin{array}{l}\text { Hydrodynamic } \\
\text { laws }\end{array}$ \\
\hline $\begin{array}{l}\text { Water } \\
\text { information } \\
\text { network }\end{array}$ & $\begin{array}{l}\text { The information } \\
\text { transmission of } \\
\text { wired and wireless } \\
\text { access }\end{array}$ & $\begin{array}{l}\text { Information } \\
\text { collection, storage } \\
\text { and information } \\
\text { management } \\
\text { platform }\end{array}$ & $\begin{array}{l}\text { The flow of } \\
\text { information, }\end{array}$ & $\begin{array}{l}\text { Data standard, } \\
\text { network protocol, } \\
\text { transmission } \\
\text { protocol etc. }\end{array}$ \\
\hline $\begin{array}{l}\text { Water } \\
\text { dispatch } \\
\text { network }\end{array}$ & $\begin{array}{l}\text { The water } \\
\text { administration } \\
\text { vertical } \\
\text { management and } \\
\text { horizontal } \\
\text { coordination system }\end{array}$ & $\begin{array}{l}\text { The different levels } \\
\text { of management } \\
\text { organizations and } \\
\text { institutions }\end{array}$ & $\begin{array}{l}\text { The business } \\
\text { flow }\end{array}$ & $\begin{array}{l}\text { The rules and } \\
\text { regulations and } \\
\text { scheduling rules }\end{array}$ \\
\hline
\end{tabular}

Table 1 Network elements for intelligent water networks

The basic structure of "three layers and four components" of intelligent water network is not only the description tool of the intelligent water network system, but also the important thinking mode of analyzing the characteristics of intelligent water network and promoting the construction of intelligent water network project. The evaluation of intelligent network engineering construction of water level, the content of the construction, the establishment of intelligent smart water network construction targets are required in accordance with the characteristics of the intelligent network of "triple play", to study separate network and converged network of two modes. The construction contents of water physical network, water information network and water dispatching network can be concretely divided into channel construction, node construction and rule construction. The regulation and smoothness of "flow" in each link of water network system is an important basis for evaluating the performance of water network. 


\subsection{The overall framework design of Beijing intelligent water network}

In view of the characteristics of Beijing water physical network, water information network and water dispatching network, we put forward the overall framework of Beijing intelligent water network, as shown in figure 2.

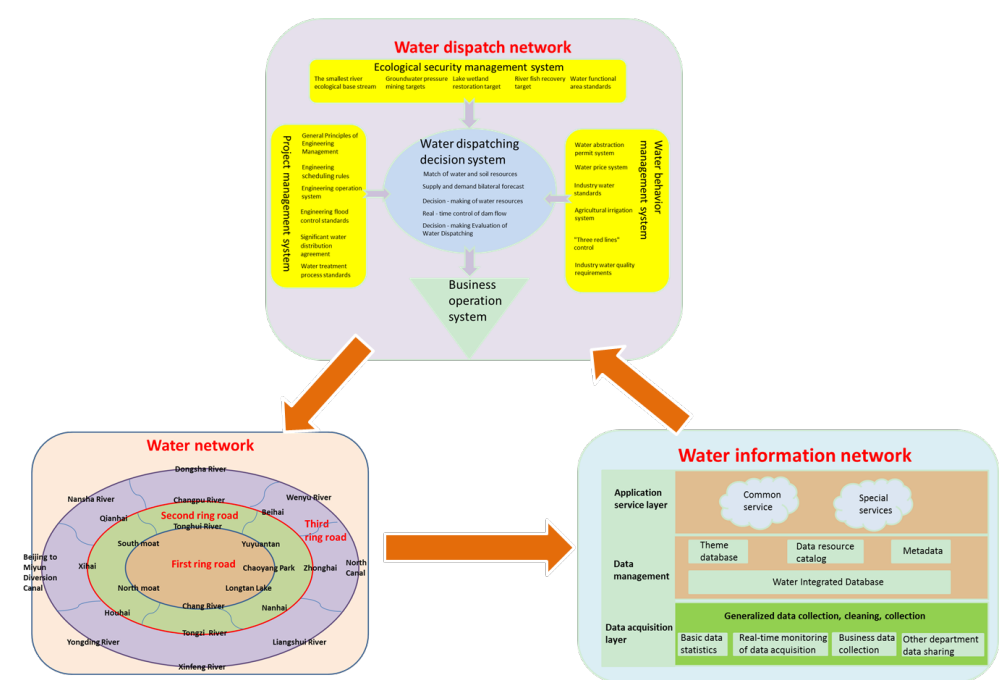

Figure 2: Beijing intelligent water network

\section{(1) Beijing Intelligent water physical network layout}

Beijing water physics network is the water grid paatern for the establishment of "three water adjustments to meet the supply, three rings of clear water around the capital". The first is to connect "Six Seas", Tongzi river and Changpu river and other rivers and lakes to form about 20km of "the first ring" ring water. water circulation can be achieved through the implementation of water purification projects and clear water supplement. The second is to connect the long river, the northern moat, the southern moat, Tonghui Rivera other 10 rivers and Yuyantan, Longtan Lake, Chaoyang Park and lakes in other 8 parks to form about $60 \mathrm{~km}$ of "the second ring" ring water. Rivers and Lakes connection and water quality improvement projects should be implements from Qinghe river to Yuanmingyuan lake, the long river $t$ Zizhuyuan Lake and Zoo lake and other rivers and the water circulation project should be implemented in the Xuaoyue river, North Touching ditch, Erdaogo ditch, Northern moat and southern moat. The third is to connect Yongding river, Beijing diversion canal, the North canal and Dongsha river, Beisha river, Nansha river, Liangshui river and Xinfeng river $t$ form about 230km of "the third ring" ring water, through Mentougou, Tongzhou, Shunyi, Changing, Dating and other areas. 


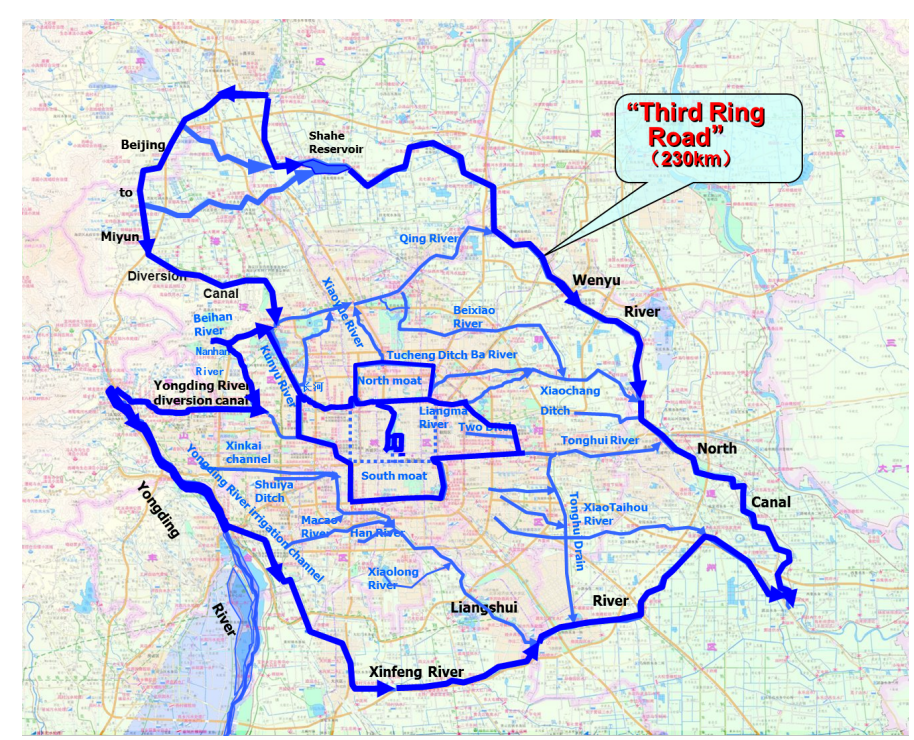

Figure 3: Beijing intelligent water physical network

\section{(2) Beijing intelligent water information network layout}

The water information network is developed in order to meet the goal of scientific decisionmaking, management synergy, control automation and service initiativation, with the general structure including generalized data acquisition system, data management system and application service system. From the perspective of business management, the data acquisition system includes includes four monitoring systems: flood monitoring system, water resources monitoring system, water environment monitoring system and water ecological monitoring system. The data storage system is based on the data collection and storage, information service and application support function established in Beijing, combining the changes of data dimension and data characteristic brought by the new technology which is represented by the Internet of Things, to seek reasonable data model and data management architecture. The application service system is to use the cloud computing model to complete water information network construction mode and conduct unified construction of the data, hardware platform, database software and the core application system, composing integrated and flexible water cloud data center architecture. It also provide targeted information services with information-dissemination in variety of forms and of high level visualization based on the software and service model of cloud computing, for the all users of Water Authority. The components of Beijing water information network is shown in figure 3. 


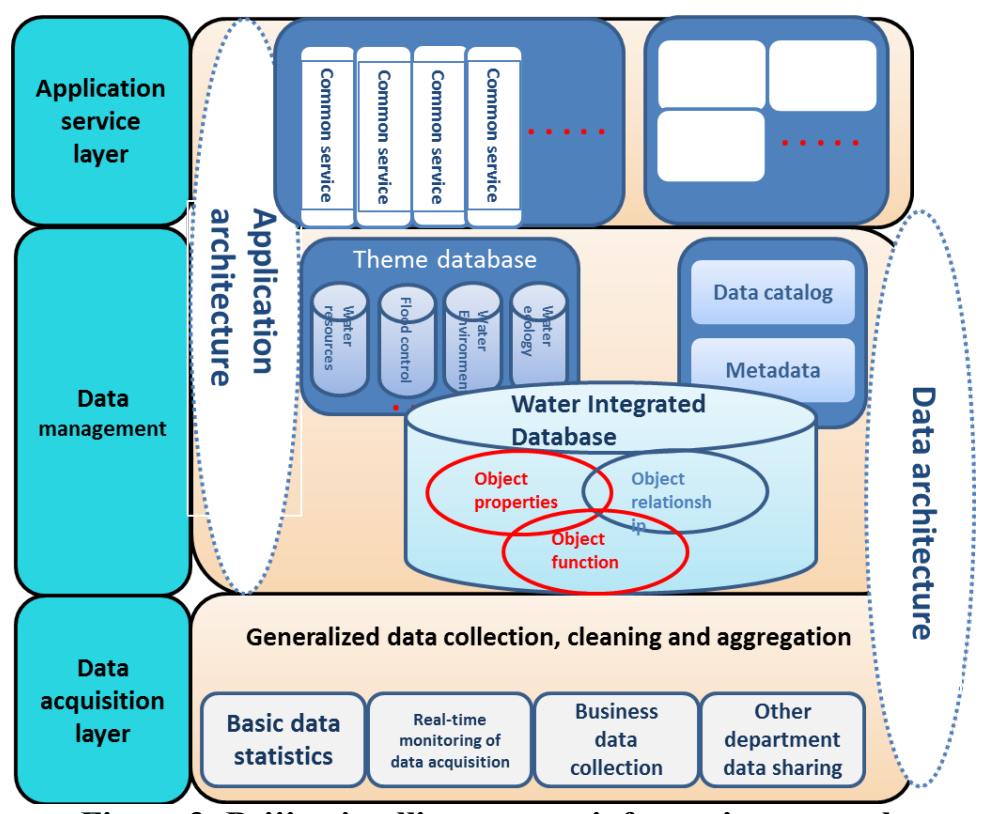

Figure 3: Beijing intelligent water information network

\section{(3) Beijing intelligent water dispatching network layout}

The water dispatching network is aimed for real-time monitoring and three-dimensional visualization, gas-land coupling and rolling forecasting, rational allocation and comprehensive scheduling, intelligent calculation, artificial decision making, ecological security, flood prevention and utilization, to build a structure composed of ecological security management system, project management system, water behavior management system, water dispatching decision system and business operation system. The ecological security management system includes the minimum ecological base flow of rivers and lakes, the goal of ground water pressure mining, the restoration target of lake wetland, the goal of river fish recovery and the standard of water function area. The project management system includes engineering management rules, engineering operations rules and engineering operation system, engineering flood prevention standard, significant water source management protocol and water treatment technological standard. Water behavior management system includes water abstraction management system, water price system, water supply system, industry water standard, agriculture irrigation system, "three red lines" control and industrial water quality requirements, etc. The water dispatching decision system includes water and soil resource matching, bilateral forecast of supply and demand, decision-making of water resources dispatching, real-time control of dam, water dispatching decision-making assessment.Business operation system includes flood control and drought relief system, water resources management system, water ecological environment protection system, water conservancy project management system. The components of Beijing Water Dispatching Network is shown in figure 4. 


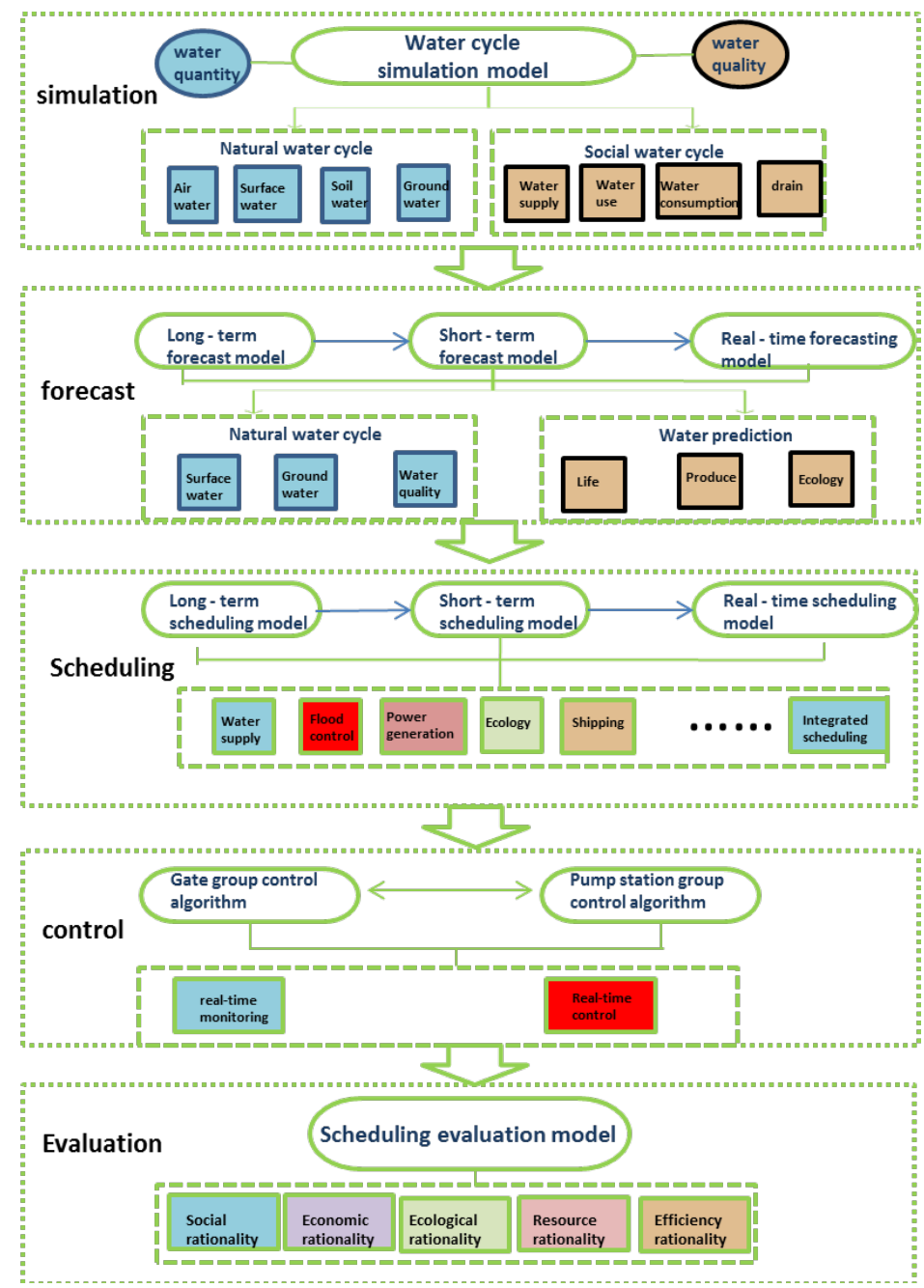

Figure 4: Beijing intelligent water dispatching network

\section{Conclusion}

Intelligent water network refers that the modern human society implement the hardware and software network system for "natural-social" dual water cycle process control in order to achieve the targets of water benefiting, disaster reduction and water-human harmony. The construction of intelligent water network includes the construction of water physical network composed of various types of water flow control infrastructure, water information construction which conforms to the trend of intelligent technology characteristics, and the construction of water dispatching network with the realization system of institutional mechanism construction and control decision making as the main content, Is the practice of water control integrated platform and integrated carrier. Intelligent water network project has achieved the integration of the three water conservancy, including the physical basis, information system and decision-making system, to achieve the flood control, water supply, 
ecological maintenance, environmental essence, power generation and other major functions of water conservancy co-ordination. Channel, node, flow and rules are the four basic elements for the water physical network, water information network and water dispatch management network together to constitute a network system. The core feature of intelligent water network is intelligent, with performance of security: target security, strong control , engineering safety; high efficiency: reasonable layout, cost-effective, advanced technology; friendly: eco-friendly, interest related friendly and human-engineering friendly.

On the basis of analyzing and diagnosing the status and problems of water network, water information network and water dispatching network in Beijing, with the urgent need of flood control and disaster mitigation, ecological environment protection and water conservancy project operation in Beijing, Beijing intelligent water network general structure is presented under the basic structure of intelligent water network, aiming for the features of Beijing water physical network, water information network and water dispatching network. The interconnection and circulation of the Beijing-Tianjin-Hebei integrated water network and the "three-ring water system" in Beijing are established. According to the characteristics of the whole county water system, the watershed water system is connected and the regional water circulation project is constructed according to the characteristics of the whole water system. The real data of the water physical network is obtained quickly, efficiently and accurately through the support of the water information network and the support system of the water information network, and the powerful data mining through the water information network decision support system is realized by using the new pattern of regional water recycling and forming the water network of Beijing. The water dispatching network forms the dispatch management instruction under the aid of the decision making support and the high speed transmission capability of water information network. The water physical network receives the instruction of the water dispatching networked and returns to current state to the dispatching network through the monitoring terminal of the water information network, able to assist the formation of the next cycle of dispatching decision.

\section{References}

Boulos P F. Smart Water Network Modeling for Sustainable and Resilient Infrastructure. Water Resources Management, 2017, 31:1-12.

Franchini M, Brunone B. Innovative and sustainable methodologies for smart water network management. Civil Engineering \& Environmental Systems, 2016, 33(1):1-2.

Nardo A D, Natale M D, Santonastaso G F, et al. An Automated Tool for Smart Water Network Partitioning. Water Resources Management, 2013, 27(13):4493-4508.

Smith V L, Murphy J J, Dinar A, et al. The Design of Smart Water Market Institutions Using Laboratory Experiments, Environmental and Resource Economics. 2000. 